\title{
Nonlinear Dynamics in Term Structure of Interest Rates: Evidence from the Euro Area
}

\author{
Ayşen ARAÇ, Department of Economics, Faculty of Economics and Administrative Sciences, Hacettepe \\ University, Turkey; e-mail: aysens@hacettepe.edu.tr
}

\section{Faiz Oranlarının Vade Yapısında Doğrusal Olmayan Dinamikler: Euro Bölgesi Örneği}

\begin{abstract}
The long run relationship between short term and long term interest rates has drawn much attention since European sovereign debt crisis in 2011-2012. Motivated by this observation, this paper investigates the expectations hypothesis $(\mathrm{EH})$ of term structure of interest rates in the euro area for the 2000:01-2014:04 period. By using the nonlinear cointegration approach developed by Kapetanios et al. (2006), we find that the long run relationship between long term and short term interest rates is stable with nonlinear adjustment. Our results provide evidence in favour of the EH. Moreover, the findings suggest that nonlinear mean reversion effects of the cointegrating residuals increase with the maturity of interest rates.

Keywords $\quad$ : Term Structure of Interest Rates, Expectation Hypothesis, Nonlinear Cointegration.

JEL Classification Codes : $\quad$ E43, C22.

$\ddot{\mathbf{O z}}$

K1sa dönem ve uzun dönem faiz oranları arasındaki uzun dönem ilişkisi, 2011-2012'de Avrupa'da gerçekleşen borç krizinden bu yana oldukça ilgi çeken bir konu olmuştur. Buradan hareketle, bu çalışmada faiz oranlarının vade yapısını açıklamakta kullanılan beklentiler teorisi, 2000:01-2014:04 dönemi Euro bölgesi örneğinde araştırılmıştır. Kapetanios vd. (2006) tarafından geliştirilmiş olan doğrusal olmayan eş-bütünleşme yaklaşımı kullanılarak, kısa dönem ve uzun dönem faiz oranları arasındaki ilişkinin doğrusal olmayan bir uyum mekanizmasıyla durağan olduğu bulunmuştur. Çalışma sonuçları beklentiler hipotezini destekler niteliktedir. Ayrıca, çalışma bulgularına göre eş-bütünleşme hata terimlerinin doğrusal olmayan ortalamaya dönüş etkisi faiz oranlarının vadesiyle artmaktadır.
\end{abstract}

Anahtar Sözcükler $\quad$ : Faiz Oranlarının Vade Yapısı, Beklentiler Hipotezi, Doğrusal Olmayan Eş-bütünleşme. 


\section{Introduction}

The issue concerning the long run relationship between long term and short term interest rates has attracted much attention since the European sovereign debt crisis in 2011 2012 in the wake of the 2008-2009 global financial crisis. In response to the crisis, along with political measures and bailout programmes being implemented in the euro area, European Central Bank (ECB) has lowered short term interest rates to near zero bound, with clear implications for the expected future short term interest rates. Motivated by such heightened importance of the term structure of interest rates in the euro area, we investigate the expectations hypothesis (henceforth $\mathrm{EH}$ ) of term structure of interest rates for the case of the euro area as a whole.

The EH states that long term interest rate is a weighted average of present and expected future short term interest rates. The important policy implication of the $\mathrm{EH}$ is that it constitutes a channel in which policymakers can change the long term prospects of an economy by targeting present short term interest rates and by manipulating the expectations on future short term interest rates. For example, when the EH holds, if a policymaker adopts policies that lower present and/or expected future short term interest rates, then long term interest rates will be lower and consequently, investment and economic growth will be higher.

Due to the importance of the long run relationship between long term and short term interest rates for policy makers, the $\mathrm{EH}$ has been intensively investigated since the seminal studies of Campbell and Shiller $(1987,1991) .{ }^{1}$ Campbell and Shiller $(1987,1991)$ were the first to use the linear cointegration approach in order to test the EH. They suggest that when short and long term interest rates are integrated of order one (or I(1)), and they tend to move together, enabling them to be cointegrated, then the EH holds true. This implies that the yield spread between long term and short term interest rates predicts future changes in interest rates. Following Campbell and Shiller (1987, 1991), the linear cointegration approach is used by a large number of studies, a long list of which includes Hall et al. (1992), Taylor (1992), Engsted and Tanggaard (1994), Mustafa and Rahman (1995), Siklos and Wohar (1996), Cuthbertson (1996). ${ }^{2}$ Although Hall et al. (1992), Engsted and Tanggaard (1994) and Siklos and Wohar (1996) provide support for the EH, the results of Taylor (1992)

1 See Shiller (1990) for a survey of theoretical and empirical studies up to 1990.

2 For a longer list, see, for example, Durré (2006), which tabulates a large number of studies and their main results. 
and Mustafa and Rahman (1995) suggest that the EH does not hold. Cuthbertson (1996) reported mixed results regarding the validity of the $\mathrm{EH}$.

Another common feature of the aforementioned studies is that they implicitly assume that portfolio adjustments are costless in asset market. When portfolio adjustment is costless, whenever arbitrage opportunities occurs, investors are assumed to change their portfolios to maximize profit. However, in the presence of transaction costs, investors tend to adjust their portfolios if they can get profit from arbitrage beyond transaction costs. This implies the existence of a band around the long run equilibrium in which there is no tendency of portfolio adjustment. Outside this band, arbitrage becomes profitable, which forces the market back towards the band. Therefore, the presence of transaction costs requires the notion of nonlinearities such as different regimes in portfolio adjustment.

In this study, bearing in mind that ignoring nonlinearities can be a theoretical drawback that limits the empirical performance of term structure models, we take into consideration the presence of nonlinearity resulted from transaction costs in order to investigate the validity of the $\mathrm{EH}$.

Recently, a growing number of studies have found support for the EH by addressing nonlinearities. Among others, Anderson (1997) employed the nonlinear error correction models to study how transaction costs affect yield movements in the US Treasury bill market for 1984:06-1993:09 period. When the results are compared with linear models which assumes no transaction, he found that nonlinear models work better than linear models. Enders and Granger (1998) applied Momentum threshold model by using US term structure of interest rates for the 1958:Q1-1994:Q1 period. The results of their study suggest that the movements of long term and short term interest rates toward the equilibrium is asymmetric. Bachmeier (2002) estimated a semiparametric error correction model (ECM) by using monthly US term structure data over the period 1952-1991. The results of his study suggest that there are nonlinear adjustments in the error correction term. Hansen and Seo (2002) applied a two regime vector error correction model with a single cointegrating vector by using US data and the 1952-1991 period. They found strong evidence for a threshold effect in the term structure of the interest rates in US. Clements and Galvao (2003) tested nonlinear system versus linear system to investigate responses of a change in short rates to past values of the spread for US Treasury bill market for the 1953:04-2001:10 period. While the results based on linear VAR model does not support the EH, the results based on threshold VAR model are in favour of the EH. Clarida et al. (2006) applied a nonlinear multivariate vector equilibrium error correction model framework that allows for asymmetric adjustment and regime shifts. Using data for the 1982-1991 period from US, Germany and Japan, they found strong evidence of the nonlinearities and asymmetries in the term structure. Mili et al. (2012) investigated the EH by using a parametric nonlinear 
inference approach for the 2001:06-2011:04 period on US data. They found evidence of nonlinearities in the relationship between interest rates changes and the spread.

Our approach in this paper is different from the previous studies on the EH. This study adopts the nonlinear cointegrating approach developed by Kapetanios et al. (2006). The nonlinear cointegration approach incorporates a nonlinear equilibrium process that is based on the principles of smooth transition auto regressive (STAR) models. STAR framework is more appropriate to test the EH for two reasons in presence of transaction costs compared to simple threshold and Markov regime switching models, which impose an abrupt change in coefficients. First, STAR modelling approach allows one to choose the appropriate type of the transition function unlike other regime-switching models. In presence of transaction costs, the profits from arbitrage, which is generally thought to be the force behind maintaining the $\mathrm{EH}$, do not compensate the costs involved in the necessary transactions for small deviations from the equilibrium. For this reason, the regimes ought to be associated with small and large distances from the long run equilibrium. The equilibrium process specified as a STAR model with the exponential transition function, which results in ESTAR model, can capture this form of regime-switching behavior. Second, the size of the deviation from equilibrium that investors can respond to might not be the same for all investors since transaction costs are peculiar to the corresponding portfolio adjustments. ${ }^{3}$ If size of the deviation from equilibrium is large, the profitability of arbitrage is greater for more investors than when it is small owing to the individually specific transactions costs. As a result, the speed of adjustment towards equilibrium varies inversely with the size of the deviation from equilibrium itself (Kapetanios et al. 2003). Unlike the other regime switching models, the nonlinear cointegration approach, assuming the change in speed of the adjustment process to be smooth rather than sharp as with TAR models, uses an equilibrium process where its error correction adjustment is slower when the cointegrating residual is close to zero.

In this study, we use a data set consisting of long term and short term interest rates from the euro area for the 2000:01-2014:04 period. Many authors have investigated the EH by using data from European countries. However, to the best of our knowledge, none of them have applied the nonlinear cointegration approach for the case of the euro area as

3 There are many factors which can cause transaction costs to be specific to the related portfolio adjustments. For instance, utility changes implied by trading, the time spent obtaining information and organizing the transaction, brokers'fees and tax liabilities as the bills are liquidated can vary with portfolio adjustments (Anderson 1997). 
whole. ${ }^{4}$ Yet more, the studies on European countries have reported mixed results regarding the validity of the EH. On one hand, for example, Gerlach and Smets (1997) and Koukouritakis and Michelis (2008) reported evidence in favor of the EH for 17 European and 11 new member countries of European Union, respectively. Musti and D'Ecclesia (2008) found evidence supportive of the EH for Italy. On the other hand, for example, Wolters (1998) reached the conclusion that the (strong form of) EH does not hold while Durré (2006) concluded that it is possible to support the (weak form of) EH (including a constant liquidity premium) for Germany. Koukouritakis (2013) showed that the empirical findings are against the EH for the whole maturity spectrum in case of France, Germany, Italy and Spain. However, he also reported evidence in favor of the $\mathrm{EH}$ for specific spreads of France, Germany and Italy.

The main novelty of this study is that we calculate the expected mean reversion effects of small and large size of shocks to cointegrating residual away from zero during the subsequent period by using the estimates of the ESTAR models. Besides, this study reveals the expected mean reversion effects of different maturities in the euro area. In passing, in this study we also carry out the linear cointegration tests developed by Johansen and Juselius (1990) in order to observe whether different econometric methodologies can lead one to reach mixed conclusions regarding the validity of $\mathrm{EH}$.

The remainder of this paper is organized as follows. Section 2 provides a brief description of the theoretical framework of the EH. Section 3 introduces econometric methodology. Section 4 presents data used in this study and empirical results. Last section draws conclusions and explains their policy implications.

\section{Theoretical Framework}

The EH implies that the yield to maturity on a long-term bond is the average of the current short yield and the expected future yields on the bonds of shorter maturities. This is called the strong or pure form of the EH. The EH is said to be of the weak form if a liquidity premium is added to the average. The general statement of the $\mathrm{EH}$ is given by Hall et al. (1992) as follows:

4 Maki (2006) used Japan data and applied the nonlinear cointegration approach to test the EH. He concluded that this approach provides clear evidence for the EH. 
$R(k, t)=\frac{1}{k}\left[\sum_{j=1}^{k} E_{t}[R(1, t+j-1)]\right]+L(k, t)$

$R(k, t)$ is the continuously compounded yield on time $\mathrm{t}$ and maturity of the $k$ period, $E_{t}$ is the expectation operator conditioned on information available at time $t$, and $\mathrm{L}(k, t)$ is the liquidity premium of the $k$ period. The existence of premium arises from interest rate risk and investor risk aversion. The pure expectations hypothesis claims that $\mathrm{L}(k, t)$ is zero, while other versions of the expectations hypothesis claim that it is constant over time. Other assumptions about the liquidity premium are made under different theories about the term structure.

Let the vector series $y(t)=(R(k, t), R(1, t))^{\prime}$ have only integrated of order one, (or $I(1)$ ), components. If it is possible to find vectors of constants $\alpha_{1}, \alpha_{2}, \ldots, \alpha_{r}$ such that the linear combinations $\alpha_{i}{ }^{\prime} y(t)$ are all $I(0)$ then $y(t)$ is said to be cointegrated, and the vectors $\alpha_{1}, \alpha_{2}, \ldots, \alpha_{r}$ are defined as cointegrating vectors.

Assuming the yield to maturity on a long-term bond $R(k, t)$ and that on 1 period bond $R(1, t)$ are $I(1)$, the possibility that they might be cointegrated is observed by rearranging Eq. (1) to obtain yield spread, $S(k, 1, t)$, as in Eq. (2).

$$
\begin{gathered}
S(k, 1, t)=[R(k, t)-R(1, t)]=\frac{1}{k} \sum_{i=1}^{k-1} \sum_{j=1}^{j=i} E_{t} \Delta R(1, t+j)+L(k, t) \\
=\mu_{t}
\end{gathered}
$$

where $\Delta R(k, s)=R(k, s)-R(k, s-1)$.

The right hand side of Eq. (2) is stationary if $\Delta R(1, t)$ and the premium $L(k, t)$ are stationary. Given these conditions, it follows that $[R(k, t)-R(1, t)]$ is stationary and that $(1,-1)^{\prime}$ is a cointegrating vector for $y(t)$. This implies that each yield $R(k, t)$ is cointegrated with $R(1, t)$, and that the spreads between $R(k, t)$ and $R(1, t)$, defined by $S(k, 1, t)$, are the stationary linear combinations of $y(t)$ which result from the cointegration of $y(t)$.

Eq. (2) shows that the difference between the observed yield spread $S(k, 1, t)$ and its market value, represented by $\mu_{t}$, must be 0 when market is in the long run equilibrium. The EH is maintained when investors are indifferent between holding a bill with $k$ period 
left to maturity and investing a sequence of one period bills for successive periods up to $k$ period. This is called "no arbitrage" condition.

The financial market is, however, likely to deviate from the long run equilibrium in the short run if portfolio adjustment is not instantaneous. Whenever the market deviates from the long run equilibrium, arbitrage opportunity occurs and it leads the market to its long run equilibrium. In particular, arbitrage opportunity can be expressed as $S(k, 1, t)-$ $\mu_{t} \neq 0$. In order to examine the attraction to the long run equilibrium, one can separately observe the cases of $S(k, 1, t)-\mu_{t}>0$ and $S(k, 1, t)-\mu_{t}<0$. In the first case, holders of 1 period bills will want to switch their bills with $\mathrm{k}$ period bills. This puts downward pressure on the spread. Conversely, if $S(k, 1, t)-\mu_{t}<0$, holders of $\mathrm{k}$ periods bills will want to switch their bills with 1 period bills, which puts upward pressure on the spread. Consequently, the difference between the observed yield spread and its market value reaches 0 . Therefore, the speculative behaviour produces the portfolio adjustments in a way that eliminates arbitrage opportunity.

If $R(k, t)$ and $R(1, t)$ have a unit root, the cointegration relationship described above can be tested for the pre-specified cointegrating vector such as $(1,-1)^{\prime}$ by using unit root tests, including that of Dickey and Fuller (1979). However, the long run equilibrium relationship does not necessarily have an ex ante one-to-one proportional relationship (Maki 2006). Instead, the following long run relationship with a relaxed form can be estimated:

$R(k, t)=\gamma_{0}+\gamma_{1} R(1, t)+\mu_{t}$

Here $\gamma_{0}$ is a constant, $\gamma_{1}$ is a cointegrating vector and $\mu_{t}$ is the disturbance term.

\section{Econometric Method}

In this study, in order to investigate the $\mathrm{EH}$, we apply the nonlinear cointegration approach proposed by Kapetanios et al. (2003, 2006). They suggest that the long run equilibrium process can be modelled with the disturbance term $\mu_{t}$ of the regression in Eq. (3) following nonlinear dynamic:

$\mu_{t}=\beta \mu_{t-1}+\gamma \mu_{t-1} \Theta\left(\theta ; \mu_{t-1}\right)+\epsilon_{t} \quad t=1, \ldots, T$

$\beta$ and $\gamma$ are unknown parameters and $\epsilon_{t}$ is independent and identically distributed white noise disturbance with zero mean and constant variance. $\Theta\left(\theta ; \mu_{t-1}\right)$ is a transition function with the range of $[0,1]$. It is assumed that $\theta \geq 0$ for identification purposes. 
The nonlinear cointegration approach uses a STAR model to capture the regimeswitching behavior. In existence of transaction costs, it appears more appropriate to specify the transition function in such a way that the regimes are associated with small and large absolute values of $\mu_{t-1}$. This can be achieved by using the exponential function

$\Theta\left(\theta ; \mu_{t-1}\right)=1-\exp \left(-\theta \mu_{t-1}^{2}\right)$

where $\Theta(\theta ; 0)=0$ and $\lim _{\mu_{t-d} \rightarrow \mp \infty} \Theta\left(\theta ; \mu_{t-1}\right)=1$.

The resultant exponential STAR (ESTAR) model can be derived from Eq. (4) and Eq. (5) and transformed to first differences form:

$$
\begin{aligned}
\Delta \mu_{t}= & \phi \mu_{t-1}+\gamma \mu_{t-1}\left[1-\exp \left(-\theta \mu_{t-1}^{2}\right)\right]+\epsilon_{t} \\
& \text { with } \phi=\beta-1
\end{aligned}
$$

A null hypothesis of no cointegration implies that $\phi=0$ and $\theta=0$ in Eq. (6). The alternative hypothesis that $\mu_{t}$ is a nonlinear globally stationary process is that $\phi=0$, $\theta>0$ and $-2<\gamma<0$.

Imposing $\phi=0$, gives the specific ESTAR model as

$$
\Delta \mu_{t}=\gamma \mu_{t-1}\left[1-\exp \left(-\theta \mu_{t-1}^{2}\right)\right]+\epsilon_{t}
$$

The null hypothesis of no cointegration thus depends on only $\theta$. In particular, one must test $H_{0}: \theta=0$ against $H_{1}: \theta>0$ and $-2<\gamma<0$. But, $\gamma$ is not identified under the null hypothesis. So the null hypothesis cannot be directly tested. In order to deal with this problem, one can compute a first order Taylor series approximation to the ESTAR model around $\theta=0$, which yields Eq. (8).

$\Delta \mu_{t}=\delta \mu_{t-1}^{3}+\varepsilon_{t}$

When the residuals in Eq. (6) are serially correlated, Eq. (8) is to be extended to the auxiliary testing regression having $\rho$-order augmentation. Kapetanios et al. (2006) propose a test statistic obtained by estimating the following approximate regression:

$\Delta \mu_{t}=\sum_{j=1}^{\rho(T)} \varphi_{j} \Delta \mu_{t-j}+\delta \mu_{t-1}^{3}+v_{t, p(T)}$ 
$v_{t, p(T)}=\sum_{j=\rho(T)+1}^{\infty} \varphi_{j} \Delta \mu_{t-j}+w_{t}$

Where $w_{t}=\varphi(L) \Delta \mu_{t}$ is the error term associated with an infinite autoregressive $A R$ representation of $\Delta \mu_{t}$ and $(L)=1-\sum_{j=1}^{\infty} \varphi_{j} L^{i}$. One need to allow $\rho(T)$ to tend to grow with $T$ for consistent estimation of Eq. (9.1). By imposing $\rho(T)=o\left(T^{\frac{1}{3}}\right)^{4}$ Kapetanios et al. (2006) derive the following $t-$ type test for $\delta=0$ in Eq. (9.1):

$t_{N E G}=\frac{\hat{\mu}_{-1}^{3 \prime} Q_{2} \Delta \hat{\mu}}{\sqrt{\hat{\sigma}_{N E G}^{2} \hat{\mu}_{-1}^{3 \prime} Q_{2} \hat{\mu}_{-1}^{3}}}$

where $\hat{\sigma}_{N E G}^{2}=T^{-1} \sum_{t=1}^{T}\left(\Delta \hat{\mu}_{t}-\tilde{\delta} \hat{\mu}_{t-1}^{3}-\sum_{i=1}^{\rho} \hat{\varphi}_{i} \Delta \hat{\mu}_{t-i}\right)^{2}, \Delta \hat{\mu}=\left(\Delta \hat{\mu}_{1}, \ldots, \Delta \hat{\mu}_{T}\right)^{\prime}, Q_{2}=I_{T}-$ $\Delta \hat{\mu}_{\rho(T)}\left(\Delta \hat{\mu}_{\rho(T)}^{\prime} \Delta \hat{\mu}_{\rho(T)}\right)^{-1} \Delta \hat{\mu}_{\rho(T)}^{\prime}, \Delta \hat{\mu}_{\rho(T)}=\left(\Delta \hat{\mu}_{-1}, \ldots, \Delta \hat{\mu}_{-\rho(T)}\right), \Delta \hat{\mu}_{-i}=\left(\Delta \hat{\mu}_{1-i}, \ldots, \Delta \hat{\mu}_{T-i}\right)^{\prime}$, $i=1, \ldots, \rho(T)$.

Kapetanios et al. (2006) tabulate the critical values of the $t_{N E G}$ tests at conventional significance levels. In case the test statistic exceeds the related critical value, the hypothesis of no cointegration can be rejected at the associated significance level.

\section{Data and Empirical Results}

\subsection{Data}

In the literature related to the $\mathrm{EH}$, a group of studies has used spot and future prices (Dwyer et al. 1996; Martens et al. 1998; Tsay 1998) while another group of studies has used interest rates of different maturities (Anderson, 1997; Brüggemann and Lütkepohl, 2005; Enders and Granger, 1998; Maki, 2006; Musti and D’Ecclesia, 2008; Tsay, 1998). This study follows the latter group since the formulations of the EH in this study are derived in terms of spread and changes in interest rates.

The data set used in this study consists of long term interest rates and several short term interest rates with different maturities from the euro area over the 2000:01-2014:04 period. Data after 2000 is preferred in order to discard the initial effects of introduction of the euro on interest rates since euro money market emerged in January 1999. 
Long term interest rates are based on the harmonized yields on member countries' government bonds with a maturity of ten years. Short term interest rates are EURIBOR (Euro Inter Bank Offered Rates) for 1-month, 3-month, 6-month and 12-month interest rates. EURIBOR, the benchmark rate of the euro money market, is the rate at which euro interbank term deposits are offered from one prime bank to another. The contributors to EURIBOR are the banks with the highest volume of business in the euro area money markets. The panel of banks consists of banks from EU countries participating in the euro from the outset, banks from EU countries not participating in the euro from the outset, large international banks from non-EU countries but with important euro area operations.

Obtained from Eurostat, all the interest rates have monthly frequencies and are expressed in percentages per annum.

\subsection{Preliminary Data Analysis}

In Fig. 1, the series used in this study are plotted against time. Here, EU-long stands for the long term interest rates. EURIBOR-1, EURIBOR-3, EURIBOR-6, EURIBOR-12 represent Euro Inter Bank Offered Rates for 1-month, 3-month, 6-month and 12-month interest rates, respectively. As shown in Fig. 1, the overall pattern in long term interest rates is that it was the highest at the beginning of the period (2000:01), the lowest at the end of the period (2014:04), increased in 2006, 2007 and 2008, before declining through to 2014 , passing by a level similar to the low recorded in 2005 . The problems regarding financing sovereign debt can be depicted by the remarkable increase in 2011.

Fig. 1 shows that short term interest rates with different maturities have followed similar paths. They increased in 2000, and then generally tended to fall during the first half of the decade, as in the case for long term interest rates. After 2005, they subsequently rose until 2007. 3-month, 6-month and 12-month interest rates peaked in the second half of 2008 ahead of long term interest rate. This reflects the effects of 2008 global financial crisis on short term interest rates. After a sharp decline in 2009, they increased in 2011 during the European sovereign debt crisis. The short term interest rates reached their lowest values around the end of the period that this study uses. 


\section{Figure: 1}

\section{Long Term and Short Term Interest Rates in the Euro Area}

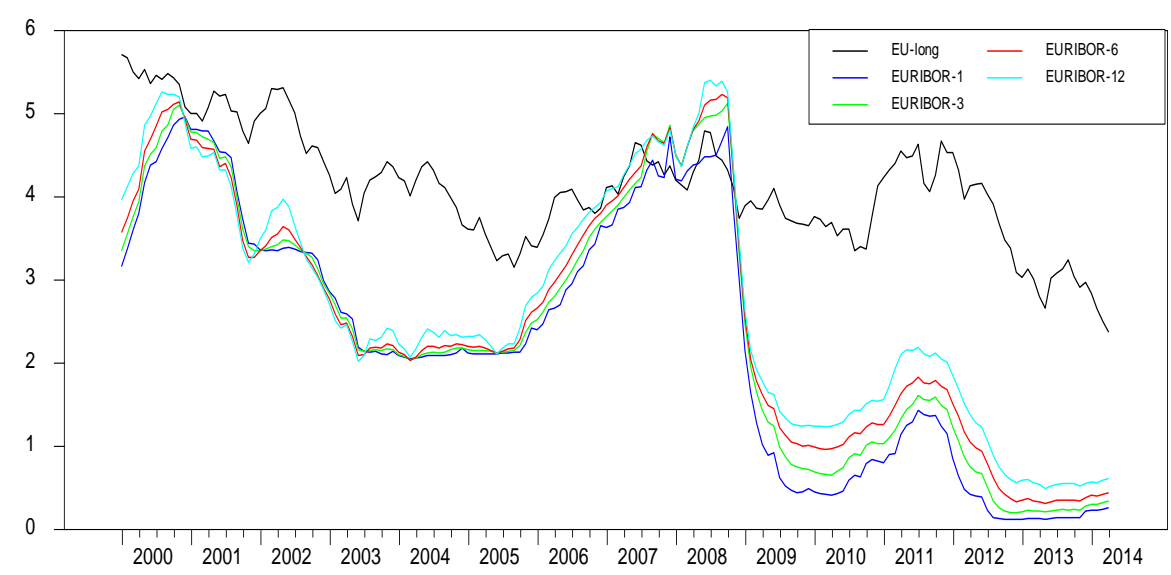

Table: 1

Descriptive Statistics

\begin{tabular}{|c|c|c|c|c|c|c|c|}
\hline Variables & Mean & SD & Min. & Max. & $\mathrm{Sk}^{\mathrm{a}}$ & $\mathrm{Ku}^{\mathrm{a}}$ & $\mathrm{J}-\mathrm{B}^{\mathrm{a}}$ \\
\hline EURIBOR-1 & 2,2958 & 1,5498 & 0,11 & 4,95 & $\begin{array}{l}0,0791 \\
(0,6748)\end{array}$ & $\begin{array}{l}-1,3005 \\
(0,0007)\end{array}$ & $\begin{array}{l}12,3007 \\
(0,0021)\end{array}$ \\
\hline EURIBOR-3 & 2,4361 & 1,5335 & 0,19 & 5,11 & $\begin{array}{l}0,1494 \\
(0,4278)\end{array}$ & $\begin{array}{l}-1,2069 \\
(0,0016)\end{array}$ & $\begin{array}{l}11,0788 \\
(0,0039)\end{array}$ \\
\hline EURIBOR-6 & 2,5467 & 1,4793 & 0,30 & 5,22 & $\begin{array}{l}0,1861 \\
(0,3233)\end{array}$ & $\begin{array}{l}-1,1399 \\
(0,0028)\end{array}$ & $\begin{array}{l}10,3054 \\
(0,0058)\end{array}$ \\
\hline EURIBOR-12 & 2,7078 & 1,4301 & 0,48 & 5,39 & $\begin{array}{l}0,2068 \\
(0,2724)\end{array}$ & $\begin{array}{l}-1,0855 \\
(0,0044)\end{array}$ & $\begin{array}{l}9,6699 \\
(0,0080)\end{array}$ \\
\hline EU-long & 4,1237 & 0,7005 & 2,36 & 5,70 & $\begin{array}{l}0,0624 \\
(0,7404)\end{array}$ & $\begin{array}{l}-0,2693 \\
(0,4799)\end{array}$ & $\begin{array}{l}0,6316 \\
(0,7292)\end{array}$ \\
\hline
\end{tabular}

Notes: Sk denotes skewness, Ku denotes excess kurtosis.

J-B denotes Jarque-Berra's test for normality of series.

${ }^{a}$ Numbers in parentheses are $p$-values.

Table 1 presents descriptive statistics of interest rates. As can be seen from Table 1 , the means of interest rates increase with maturity. The series exhibit relatively moderate 
skewness and excess kurtosis. J-B statistics for all series except EU-long suggest the rejection of the null hypothesis that series are normally distributed.

\subsection{Stochastic Properties of the Series}

Both the nonlinear cointegration approach proposed by Kapetanios et al. (2006) and the linear cointegration approach developed by Johansen and Juselius (1990) rely on the assumption that both short term and long term interest rates series are I(1). Therefore, stationarity of the variables for short term and long term interest rates are first to be checked. Taking account of the low power of conventional Augmented Dickey-Fuller (ADF) test against alternative data generating processes, Phillips-Perron (PP) tests are also applied.

Table: 2

\section{Unit Root Test Results}

\begin{tabular}{|c|c|c|c|c|}
\hline \multirow{2}{*}{ Variables } & \multicolumn{2}{|l|}{ ADF } & \multicolumn{2}{|l|}{$\mathrm{PP}$} \\
\hline & In level & In first difference & In level & In first difference \\
\hline EURIBOR-1 & $-1,2139$ & $-7,0282 * * *$ & $-1,1515$ & $-7,1372 * * *$ \\
\hline EURIBOR-3 & $-1,6486$ & $-5,3800 * * *$ & $-1,1761$ & $-5,3800 * * *$ \\
\hline EURIBOR-6 & $-1,7844$ & $-5,2000 * * *$ & $-1,1933$ & $-5,2953 * * *$ \\
\hline EURIBOR-12 & $-1,8572$ & $-5,5354 * * *$ & $-1,2766$ & $-5,5304 * * *$ \\
\hline EU-long & $-1,7016$ & $-10,3043 * * *$ & $-1,4851$ & $-10,2324 * * *$ \\
\hline
\end{tabular}

Notes: ${ }^{*}, * *, * * *$ denote significance at $10 \%, 5 \%$ and $1 \%$ level, respectively.

Table 2 presents the results of the ADF and PP tests. The lag lengths of each variable in each equation are selected by applying conventional Schwarz Information Criteria (SC). When testing for a unit root in interest rates in levels, only the intercept is included since the series do not show trending behavior over the period. When testing the null for the first differences of interest rates, the specification without an intercept is used for the reason that the intercept cancels out via differencing. As can be seen from Table 2, the series in level have unit roots. However, the results of ADF and PP tests suggest that for the series in first difference the null hypothesis of unit root can be rejected at $1 \%$ significance level. Therefore, it can be concluded that the short term and long term interest rates are integrated of order one. 
Johansen and Juselius' (1990) cointegration (henceforth JJ) tests are, then, applied in order to examine whether there are linear cointegration relationships between short and long term interest rates. The results of JJ tests appear in Table 3. All models contain only constants as deterministic components in the long run equilibrium relationship because the theory of the term structure does not support the trend. The results of the $\mathrm{JJ}$ cointegration tests are sensitive to the lag structure of the variables. For this reason, the lag lengths of each endogenous variable in each equation are selected by applying SC, and then the resultant models are tested against autocorrelation of residuals. Accordingly, the most suitable lag numbers are selected.

Table: 3

The Results of Linear Cointegration Tests

\begin{tabular}{|c|c|c|c|c|c|c|}
\hline Pairs & $\begin{array}{l}\text { Unrestricted } \\
\text { Cointegration Rank Test }\end{array}$ & $\begin{array}{l}\text { Hypothesized } \\
\text { No. of CE(s) }\end{array}$ & Eigenvalue & Statistic & $\begin{array}{l}\text { Critical } \\
\text { Value(0.05) }\end{array}$ & Probability \\
\hline \multirow{4}{*}{$\begin{array}{l}\text { EURIBOR-1 } \\
\text { and } \\
\text { EU-long }\end{array}$} & \multirow{2}{*}{ Trace } & None & 0,0388 & 8,4849 & 15,4947 & 0,4151 \\
\hline & & At most 1 & 0,0106 & 1,7920 & 3,8415 & 0,1807 \\
\hline & \multirow{2}{*}{ Maximum Eigenvalue } & None & 0,0388 & 6,6929 & 14,2646 & 0,5261 \\
\hline & & At most 1 & 0,0106 & 1,7920 & 3,8415 & 0,1807 \\
\hline \multirow{4}{*}{$\begin{array}{l}\text { EURIBOR-3 } \\
\text { and } \\
\text { EU-long }\end{array}$} & \multirow{2}{*}{ Trace } & None & 0,0376 & 8,6043 & 15,4947 & 0,4032 \\
\hline & & At most 1 & 0,0125 & 2,1199 & 3,8415 & 0,1454 \\
\hline & \multirow{2}{*}{ Maximum Eigenvalue } & None & 0,0376 & 6,4844 & 14,2646 & 0,5519 \\
\hline & & At most 1 & 0,0125 & 2,1199 & 3,8415 & 0,1454 \\
\hline \multirow{4}{*}{$\begin{array}{l}\text { EURIBOR-6 } \\
\text { and } \\
\text { EU-long }\end{array}$} & \multirow{2}{*}{ Trace } & None & 0,0361 & 8,9839 & 15,4947 & 0,3669 \\
\hline & & At most 1 & 0,0163 & 2,7737 & 3,8415 & 0,0958 \\
\hline & \multirow{2}{*}{ Maximum Eigenvalue } & None & 0,0361 & 6,2103 & 14,2646 & 0,5864 \\
\hline & & At most 1 & 0,0163 & 2,7737 & 3,8415 & 0,0958 \\
\hline \multirow{4}{*}{$\begin{array}{l}\text { EURIBOR-12 } \\
\text { and } \\
\text { EU-long }\end{array}$} & \multirow{2}{*}{ Trace } & None & 0,0357 & 9,4972 & 15,4947 & 0,3214 \\
\hline & & At most 1 & 0,0197 & 3,3581 & 3,8415 & 0,0669 \\
\hline & \multirow{2}{*}{ Maximum Eigenvalue } & None & 0,0357 & 6,1391 & 14,2646 & 0,5954 \\
\hline & & At most 1 & 0,0197 & 3,3581 & 3,8415 & 0,0669 \\
\hline
\end{tabular}

The results of the $\mathrm{JJ}$ cointegration test suggest no cointegration relationship between short term and long term interest rates at the 5\% significance level. Therefore, according to the linear cointegration tests results, long term and short term interest rates are expected to drift far apart in the long run. 


\subsection{The Nonlinear Cointegration Tests and the Expected Mean Reversion Effects}

After we found no linear cointegration relationship between long term and short term interest rates, we employed the nonlinear cointegration tests to investigate whether or not cointegrating residuals show globally stationary processes. As in the case of JJ tests, only constants are used as deterministic components in the long run equilibrium relationships. A general-to-specific modelling approach is applied to determine $\rho$ in Eq. (9.1). The auxiliary regressions for $\rho=12$ are first estimated and then all insignificant lags are dropped.

The results for the nonlinear cointegrating tests are given in Table 4. Critical values of the $t_{N E G}$ tests at $10 \%, 5 \%$ and $1 \%$ significance level for the intercept case are $2,98,-3,28$ and $-3,84$, respectively. As Table 4 shows, all nonlinear $t_{N E G}$ tests reject the null hypothesis of no cointegration at $5 \%$ significance level. Therefore, the nonlinear cointegration tests results suggest that long run relationships between long-term and each short-term interest rates are stable and that cointegration errors follow nonlinear globally stationary processes.

Table: 4

\section{The Results of Nonlinear Cointegration Tests}

\begin{tabular}{|c|c|c|c|c|c|}
\hline Explanatory Variable & Lag order $(\rho)$ & $t_{N E G}$ & $\hat{\theta}$ & $t_{\theta}$ & p-value \\
\hline EURIBOR-1 & 1 & $-3,3378 * *$ & 0,1034 & 1,6626 & 0,0964 \\
\hline EURIBOR-3 & 1 & $-3,4016^{* *}$ & 0,1177 & 1,7988 & 0,0721 \\
\hline EURIBOR-6 & 1 & $-3,4948 * *$ & 0,1469 & 1,9212 & 0,0547 \\
\hline EURIBOR-12 & 1 & $-3,4361 * *$ & 0,2048 & 2,0863 & 0,0370 \\
\hline
\end{tabular}

The ESTAR models are, then, estimated under the alternative hypothesis of cointegration by using the nonlinear least squares technique. Focusing on the bivariate models, the nonlinear least squares estimates of $\theta$ s are obtained from the alternative ESTAR models. $\gamma=-1$ is imposed to circumvent the identification problems and for nonlinear algorithms not to fail to converge, as Kapetanios et al. (2006) recommend.

The results for the estimated $\theta s,(\hat{\theta})$, their $t$-statistics and $p$-values are given in Table 4. Here, $t$-statistics can be referred to as significant if an asymptotic $90 \%$ confidence 
interval around the estimate excludes zero. Hence, $\hat{\theta}$ s can be accepted as significant in all cases. $\hat{\theta} s$ vary between 0,1034 and 0,2048 .

Figure: 2

\section{The Transition Functions against the Associated Cointegrating Residuals}
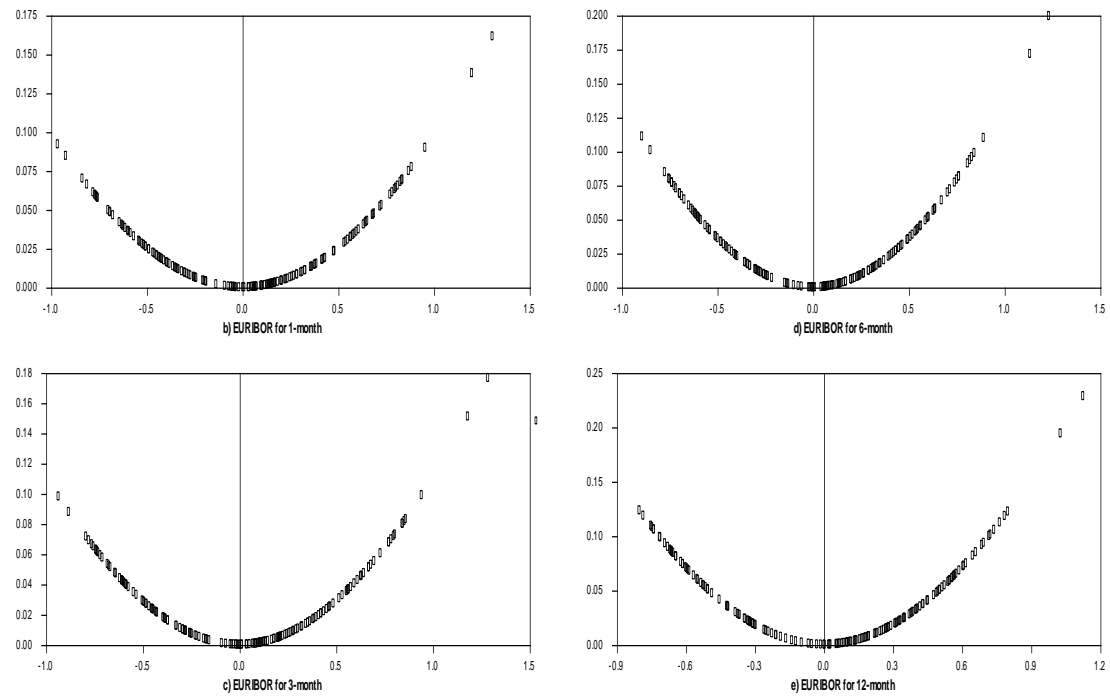

The dependence of the speed of adjustment towards equilibrium on the position of the system can straightforwardly be observed by plotting the transition function at estimated $\theta$ against the cointegrating residual. Fig. 2 displays the transition functions at corresponding $\hat{\theta}$ s against cointegrating residuals for all cases. Note that apart from a very few observations in each case, each of the cointegration residuals varies within two standard deviations of its respective mean. As can be seen from Fig. 2, for each case the speed of adjustment towards equilibrium decreases with the size of the shocks to each cointegrating residual away from its mean.

Based on the model used in this study, each cointegrating residual is assumed to be locally nonstationary at its mean in the absence of augmentation terms. However, when it is away from its mean, each series exhibits mean reversion. In order to observe this implication of the model, the expected nonlinear mean reversion effects are calculated. To 
calculate them, firstly, the cointegrating residuals are randomly drawn with replacement from the estimated cointegrating residuals. One and two standard deviations of each cointegrating residual are defined as a small shock and a large shock, respectively. Secondly, the values of the transition function at the associated $\hat{\theta}$ are calculated by using both small and large shock for each case of different maturities. The process above is repeated 1000 times for each case of different maturities. Finally, the calculated 1000 separate values of the transition functions are averaged, which yields the expected mean reversions' per cent of small and large size of shocks to each estimated cointegrating residual away from its mean during the subsequent period. The results are summarized in Table 5.

As shown in Table 5, nonlinear mean reversion effects of the series increase with maturity of interest rates. Over all, the cointegrating residual for the case of EURIBOR for 1 month exhibits the smallest nonlinear adjustment with about $9 \%$ of two and $2 \%$ of one standard deviation shock to the cointegrating residual from its mean being corrected during the following period. The cointegrating residual for the case with EURIBOR for 12 months has the largest mean reversion effects in all. One and two standard shocks to this cointegrating residual would be respectively followed by about $4 \%$ and $16 \%$ correction back towards its mean during the next period.

Table: 5

Mean Reversions' Per Cent of the Shocks to Cointegrating Residuals during Subsequent Period

\begin{tabular}{lcccc}
\hline Shock & $\Theta\left(\hat{\theta}_{1} ; \mu_{1, t-1}\right)$ & $\Theta\left(\hat{\theta}_{3} ; \mu_{3, t-1}\right)$ & $\Theta\left(\hat{\theta}_{6} ; \mu_{6, t-1}\right)$ & $\Theta\left(\hat{\theta}_{12} ; \mu_{12, t-1}\right)$ \\
\hline Small & 0,0248 & 0,0279 & 0,0335 & 0,0436 \\
Large & 0,0956 & 0,1071 & 0,1273 & 0,1632 \\
\hline
\end{tabular}

Notes: $\hat{\theta}_{1}, \hat{\theta}_{3}, \hat{\theta}_{6}$ and $\hat{\theta}_{12}$ represent the estimated $\theta$ s and $\mu_{1, t-1}, \mu_{3, t-1}, \mu_{6, t-1}$ and $\mu_{12, t-1}$ are the cointegrating residuals for the cases with EURIBOR for 1 month, 3 months, 6 months, 12 months, respectively. One and two standard deviations of each cointegrating residual are defined as a small shock and a large shock, respectively.

\section{Conclusion}

This paper examined the expectation hypothesis of interest rates $(\mathrm{EH})$ by using the nonlinear cointegration approach developed by Kapetanios et al. (2006) for the case of the euro area based on monthly data. Spanning the 2000:1-2014:4 period, the data set consists of EURIBOR for 1-month, 3-month, 6-month and 12-month interest rates as short term interest rates. Long term interest rates are based on the harmonized yields on member countries' government bonds with a maturity of ten years. 
Conventional approaches to examining the EH include linear cointegration tests, which is consistent with costless portfolio adjustments. However, this study takes account of transaction costs, and characterizes the long run relationship between short term and long term interest rates with a nonlinear adjustment. Unlike conventional approaches, this approach allows for different responses with respect to deviation from equilibrium and different speeds of adjustment towards equilibrium. In order to compare the results the linear cointegration tests, developed by Johansen and Juselius (1990), are also applied.

The results of linear cointegration tests imply that short-term and long-term interest rates are not cointegrated. However, the nonlinear cointegration test results suggest that long run relationship between short-term and long-term interest rates is stable with nonlinear adjustment. In contrast to the linear cointegration tests' results, the nonlinear cointegration test results support the expectation hypothesis of interest rates for the case of the euro area.

The estimates of the ESTAR models of nonlinear adjustments for the cases with EURIBOR for 1, 3, 6 and 12 months reveal that the speed of adjustment towards equilibrium decreases with the size of the shocks to each cointegrating residual away from its mean. Moreover, the calculations of the expected mean reversion effects of the cointegrating residuals indicate that they increase with maturity of the interest rates. Overall, the cointegrating residual for the case with EURIBOR for 12 months exhibits the largest, while those for the case with EURIBOR for 1 month has the smallest mean reversion effects.

The results of this study have clear policy implications. First of all, this study explicitly shows that ignoring the presence of nonlinear adjustment in the long run relationship between short term and long term interest rates can be a drawback of the term structure models of interest rates. Hence, this drawback might lead monetary authorities to misjudge the validity of the EH. Secondly, our findings suggest that ECB can affect long term interest rates by targeting short term interest rates. However, ECB should be cautious when using short term interest rates. Due to the presence of transaction costs, short term interest rates can have effects on long term interest rates only when deviation from equilibrium is large enough for investors to make profit beyond transaction costs. Otherwise, short term interest rates cannot be used as instruments. In addition, we find that ECB might expect to affect long term interest rates faster by targeting short term interest rates with longer maturity.

As a final point to note, it can be recalled that during the European sovereign debt crisis, Greece, Ireland and Portugal's default on their debts generated a lack of confidence, which, in turn, became a major source of widening the bond yield spreads and increasing risk insurance on credit default swap between these and the other member countries of the 
euro area. Although ECB has lowered short term interest rates to near zero bound as a response to the crisis, the bond yield spreads did not revert back to the positions before the debt crisis. For example, Greece has been suffering from high level of its long term interest rates while the level of German long term interest rates has been even lower than long term interest rates of the euro area. As a result, we believe that merely targeting short term interest rates at low levels does not seem sufficient to affect the long term prospects of all economics in a similar way until the confidence is restored again in the whole euro area.

\section{References}

Anderson, H.M. (1997), "Transaction costs and non-linear adjustment towards equilibrium in the US treasury bill market", Oxford Bulletin of Economics and Statistics, 59, 465-484.

Bachmeier, L. (2002), "Is the term structure nonlinear? A semiparametric investigation", Applied Economics Letters, 9, 151-153.

Brüggemann, R. \& H. Lütkepohl (2005), "Uncovered interest rate parity and the expectations hypothesis of the term structure: empirical results for the US and Europe," SFB 649 Discussion paper No 2005, 035.

Campbell, J.Y. \& R.J. Shiller (1987), “Cointegration and tests of present value models”, Journal of Political Economy, 95, 1062-1088.

Campbell, J.Y. \& R.J. Shiller (1991), "Yield spreads and interest rate movements: A bird's eye view", Review of Economic Studies, 58, 495-514.

Clarida, R.H. \& L. Sarno \& M.P. Taylor \& G. Valente (2006), "The role of asymmetries and regime shifts in the term structure of interest rates", The Journal of Business, 79, 1193-1224.

Clements, M.P. \& A.B. Galvao (2003), "Testing the expectations theory of the term structure of interest rates in threshold models", Macroeconomic Dynamics, 7, 567-85.

Cuthbertson, K. (1996), "The expectations hypothesis of the term structure: the UK interbank market", The Economic Journal, 106, 578-592.

Dickey, D.A. \& W.A. Fuller (1979), "Distribution of the estimates for autoregressive time series with a unit root", Journal of the American Statistical Association, 74, 427-31.

Durré, A. (2006), "The liquidity premium in the money market: a comparison of the German mark period and the euro area", German Economic Review, 7, 163-87.

Dwyer, G.P. \& P. Locke \& W. Yu (1996), "Index arbitrage and nonlinear dynamics between the SP500 futures and cash", Review of Financial Studies, 9, 301-32.

Enders, W. \& C.W.J. Granger (1998), "Unit root tests and asymmetric adjustment with an example using the term structure of interest rates", Journal of Business and Economic Statistics, $16,304-11$.

Engsted, T. \& C. Tanggaard (1994), “A cointegration analysis of Danish zero-coupon bond yields", Applied Financial Economics, 4, 265-78.

Gerlach, S. \& F. Smets (1997), "The term structure of euro-rates: some evidence in support of the expectations hypothesis", Journal of International Money and Finance, 16, 305-21. 
Hall, S.G. \& H.M. Anderson \& C.W.J. Granger (1992), "A cointegration analysis of treasury bill yields", Review of Economics and Statistics, 74, 116-26.

Hansen, B.E. \& B. Seo (2002), "Testing for two-regime threshold cointegration in vector errorcorrection models", Journal of Econometrics, 110, 293-318.

Johansen, S. \& K. Juselius (1990), "Maximum likelihood estimation and inference on cointegrationwith applications to the demand for money", Oxford Bulletin of Economics and Statistics, $52,169-210$.

Kapetanios, G. \& Y. Shin \& A. Snell (2003), “Testing for a unit root in the nonlinear STAR framework", Journal of Econometrics, 112, 359-79.

Kapetanios, G. \& Y. Shin \& A. Snell (2006), "Testing for cointegration in nonlinear smooth transition error correction models", Econometric Theory, 22, 279-303.

Koukouritakis, M. (2013), "Expectations hypothesis in the context of debt crisis: Evidence from five major EU countries", Research in Economics, 67, 243-58.

Koukouritakis, M. \& L. Michelis (2008), “The term structure of interest rates in the 12 newest EU countries", Applied Economics, 40, 479-90.

Maki, D. (2006), "Non-linear adjustment in the term structure of interest rates: a cointegration analysis in the non-linear STAR framework", Applied Financial Economics, 16, 130107.

Martens, M. \& P. Kofman \& T.C.F. Vorst (1998), "A threshold error-correction model for intraday futures and index returns", Journal of Applied Econometrics, 13, 245-63.

Mili, M. \& J.M. Sahut \& F. Teulon (2012), "New evidence of the expectation hypothesis of interest rates: a flexible nonlinear approach", Applied Financial Economics, 22, 165-76.

Mustafa, M. \& M. Rahman (1995), "Cointegration between US short-term and long-term interest rates (both nominal and real)", Applied Financial Economics, 5, 323-27.

Musti, S. \& R.L. D'Ecclesia (2008), “Term structure of interest rates and the expectations hypothesis: the euro area", European Journal of Operational Research, 185, 1596-1606.

Shiller, R.J. (1990), "The term structure of interest rates" in B. M. Friedman and F. H. Hahn (eds), Handbook of Monetary Economics, Vol. 1, Amsterdam: North-Holland, 627-722.

Siklos, P.L. \& M.E. Wohar (1996), "Cointegration and the term structure: A multicountry comparison", International Review of Economics and Finance, 5, 21-34.

Taylor, M.P. (1992), "Modelling the yield curve”, The Economic Journal, 102, 524-37.

Tsay, R.S. (1998), "Testing and modelling multivariate threshold models", Journal of the American Statistical Association, 93, 1188-1202.

Wolters, J. (1998), “Cointegration and German bond yields", Applied Economics Letters, 5, 497502. 
Araç, A. (2015), "Nonlinear Dynamics in Term Structure of Interest Rates: Evidence from the Euro Area", Sosyoekonomi, Vol. 23(26), 79-97. 